\title{
Overcoming Encouragement of Dragon Fruit Plant (Hylocereus undatus) against Stem Brown Spot Disease Caused by Neoscytalidium dimidiatum Using Bacillus subtilis Combined with Sodium Bicarbonate
}

\author{
Sanan Ratanaprom ${ }^{1}$, Korakot Nakkanong ${ }^{2}$, Charassri Nualsri ${ }^{2}$, Palakrit Jiwanit ${ }^{1}$, Thanyakorn Rongsawat ${ }^{3}$, \\ and Natthakorn Woraathakorn $\mathbb{D}^{1}{ }^{1 *}$ \\ ${ }^{I}$ Faculty of Science and Technology, Prince of Songkla University, Pattani Campus, Pattani 94000, Thailand \\ ${ }^{2}$ Agriculture Innovation and Management Division, Faculty of Natural Resources, Prince of Songkla University, Hat Yai \\ 90112, Thailand \\ ${ }^{3}$ Tropical Fruit and Plantation Crops Research Center, Faculty of Natural Resources, Prince of Songkla University, Hat \\ Yai 90112, Thailand
}

(Received on January 23, 2021; Revised on February 25, 2021; Accepted on March 11, 2021)

The use of the supernatant from a Bacillus subtilis culture mixed with sodium bicarbonate was explored as a means of controlling stem brown spot disease in dragon fruit plants. In in vitro experiments, the $B$. subtilis supernatant used with sodium bicarbonate showed a strong inhibition effect on the growth of the fungus, Neoscytalidium dimidiatum, the agent causing stem brown spot disease and was notably effective in preventing fungal invasion of dragon fruit plant. This combination not only directly suppressed the growth of $N$. dimidiatum, but also indirectly affected the development of the disease by eliciting the dragon-fruit plant's defense response. Substantial levels of the pathogenesisrelated proteins, chitinase and glucanase, and the phenylpropanoid biosynthetic pathway enzymes, peroxidase and phenyl alanine ammonia-lyase, were triggered. Significant lignin deposition was also detected in treated cladodes of injured dragon fruit plants in in

*Corresponding author.

Phone) +66-73-333733, FAX) +66-73-335130

E-mail)natthakorn.w@psu.ac.th

ORCID

Natthakorn Woraathakorn

https://orcid.org/0000-0002-9902-9078

Handling Editor : Mee Kyung Sang

(c) This is an Open Access article distributed under the terms of the Creative Commons Attribution Non-Commercial License (http:// creativecommons.org/licenses/by-nc/4.0) which permits unrestricted noncommercial use, distribution, and reproduction in any medium, provided the original work is properly cited.

Articles can be freely viewed online at www.ppjonline.org. vivo experiments. In summary, $B$. subtilis supernatant combined with sodium bicarbonate protected dragon fruit plant loss through stem brown spot disease during plant development in the field through pathogenic fungal inhibition and the induction of defense response mechanisms.

Keywords : Bacillus subtilis, dragon fruit plant, plant defense response, sodium bicarbonate, stem brown spot

Stem brown spot disease is an important disease of dragon fruit plants caused by Neoscytalidium dimidiatum. It is the most serious disease affecting the dragon fruit industry and has become an acute problem in many countries worldwide, including the USA, Israel, China, Indonesia, Malaysia, and Thailand (Xu et al., 2018). This disease emerged in 2010 and has recently become a difficult problem to solve. Many dragon fruit orchards have encountered $N$. dimidiatum infection and farmers have been forced to abandon those orchards because eradicating or reducing the disease is of labor- and capital-intensive. Moreover, even though all infected parts of dragon fruit plants are pruned out, new cladodes are rapidly infected by $N$. dimidiatum. Nowadays, stem brown spot disease is controlled by the intensive use of synthetic chemical fungicides. However, the continuous use of the synthetic chemical fungicides which are effective in controlling fungicide-resistant pathogen strains poses a hazard to environmental and human health because of their high toxicity.

Recently, consumer demand for safe residue-free chemi- 
cal fungicides has made their development an important research topic aimed at allowing safe sustainable dragon fruit production using eco-friendly strategies which protect dragon fruit plants from pathogenic infection. Zahid et al. (2014) developed a biofungicide capable of submicron dispersion at a concentration of $1 \%$ based on low molecular weight chitosan with a $600 \mathrm{~nm}$ droplet size. The fungicide was shown to be effective in the inhibition of diseases in dragon fruit caused by Colletotrichum gloeosporioides. In another study, a mixture of oligochitosan and nanosilica was found to be an effective elicitor of dragon fruit plant resistance to $N$. dimidiatum (Tuan et al., 2019). Meanwhile, Luong et al. (2016) screened and identified microorganisms capable of inhibiting $N$. dimidiatum growth and found that two microorganism strains, Streptomyces fradiae and Bacillus polyfermenticus possessed the desired property. Moreover, Bacillus spp. have become antagonistic bacteria of interest, which are capable of inhibiting the agents that cause of dragon fruit disease. The main mode of action of Bacillus spp. is to produce and secrete antimicrobial substances that suppress other microorganisms. Interestingly, the antimicrobial substances from Bacillus spp. are heat resistant so that autoclaving can be used in preparing them for use. Moreover, all Bacillus spp. can survive under extreme environmental conditions, such as radiation, extreme $\mathrm{pH}$, salinity, and drought as well as being resistant to solvents. These properties make Bacillus spp. appropriate for development as biological control agents. However, many previous studies have revealed that the use of antagonistic microorganisms alone to control plant diseases have often not resulted in a satisfactory outcome, and the use of microorganisms combined with other substances with the potential to increase disease control by antagonistic microorganisms has therefore been attempted. Bicarbonates have been suggested as an alternative system of plant disease control and among those, sodium bicarbonate $\left(\mathrm{NaHCO}_{3}\right)$ is particularly interesting since it has been classified as a Generally Regarded as Safe (GRAS) compound and can be used in producing foodstuffs. There have been a number of reports which have shown that $\mathrm{NaHCO}_{3}$ alone or in combination with other substances can affect the growth of plant pathogens, including Penicillium digitatum, P. italicum, and Botrytis cinerea (Ippolito et al., 2005; Youssef et al., 2014).

The aim of the research described in this paper was, therefore, to evaluate a cell-free culture of Bacillus subtilis (supernatant) in preventing and controlling dragon fruit plant disease caused by $N$. dimidiatum in combination with sodium bicarbonate. The two objectives of this study were, firstly to examine the inhibition effect of the super- natant combined with sodium bicarbonate on the growth of pathogenic fungal mycelium both in vitro and in vivo; and secondly, to investigate their effect on the elicited defense mechanisms in dragon fruit plant responses to artificially inoculated cladodes of the combined treatment, including exploring the defense-related enzyme activity and the deposition of lignin around artificial wounds on dragon fruit plants.

\section{Materials and Methods}

Dragon fruit plants. The stem brown spot disease infected samples of dragon fruit plants from infected orchard in Hat Yai district, Thailand, were used for the experiment related to disease control. The infected parts of dragon fruit plant were pruned and kept the orchard clean prior to the experiment which involved in vivo assay.

In addition, cladodes of dragon fruit plants (Hylocereus undatus) were cut from an uninfected orchard and transferred to the greenhouse nursery in the Natural Resources Faculty, Prince of Songkla University, Hat Yai, Thailand. The pieces of dragon-fruit-plant cladode were cleaned with tap water and immersed in $1 \%$ sodium hypochlorite for 5 min followed by $70 \%$ ethanol for disinfection prior to planting in pots under greenhouse conditions prior to the investigation of their induced-resistance mechanism.

B. subtilis' supernatant. B. subtilis ABS-S14 was cultured in Luria-Bertani (LB) medium at $37^{\circ} \mathrm{C}$ with continuous shaking at $200 \mathrm{rpm}$ for $72 \mathrm{~h}$. Then the vegetative cells and endospores were removed by centrifugation at $8,000 \times \mathrm{g}$ for $20 \mathrm{~min}$. The resulting supernatant was autoclaved at $121^{\circ} \mathrm{C}$ for $20 \mathrm{~min}$.

Pathogenic fungus. The fungal pathogen, $N$. dimidiatum, was isolated from infected cladodes cut from dragon fruit plants. The cladode lesions were sterilized by swabbing with $70 \%$ ethanol and then the cladodes were cut into small blocks $(0.5 \times 0.5 \times 0.2 \mathrm{~cm})$, which were immersed in $1 \%$ sodium hypochlorite for $3 \mathrm{~min}$ and washed twice with sterile distilled water. All the sterilized sample blocks were placed onto the center of potato dextrose agar (PDA) plates. The hyphae growing from the sample blocks were plugged and placed onto the center of new PDA plates. The nucleic acid from the growing mycelium was extracted and the internal transcribed spacer (ITS), translation elongation factor 1-alpha (TFE) and $\beta$-tubulin (TUB) genes amplified using the polymerase chain reaction (PCR). The PCR products were used for identification of the fungus. 
In vitro assay

Antagonist assay of $B$. subtilis on $N$. dimidiatum. The antagonistic effect of $B$. subtilis ABS-S14 on the growth of $N$. dimidiatum was investigated by a dual-culture assay. The actively growing mycelial plug of a 2-day-old colony of $N$. dimidiatum grown on PDA medium was placed in the center of a new PDA plate $(9.0 \mathrm{~cm}$ in diameter). The $B$. subtilis cells were harvested from a bacterial culture shaken overnight in LB broth by centrifugation at $8,000 \times g$ for 20 $\min$. The supernatant was discarded, and the bacterial pellet was streaked away from the growing mycelium agar plug on a PDA plates for approximately $1 \mathrm{~cm}$. The dual-inoculated plates were incubated at $25^{\circ} \mathrm{C}$, with a fungus only ( $N$. dimidiatum) plates serving as a control. Four replicates of each treatment were prepared, and the experiment was repeated twice. The inhibitory zone was recorded after the control had grown with the mycelial edge reaching the rim of the PDA medium. The radial prolongation of the mycelial growth was measured using a Vernier Caliper along two diameters positioned at right angles to one another, and the average values were calculated for each plate. The percentage of mycelial growth inhibition was calculated as follows (Gamliel et al., 1989):

$$
\text { Percentage of inhibition }=100-\left[\left(\mathrm{R}^{2} / \mathrm{r}^{2}\right) \times 100\right]
$$

, where $\mathrm{R}=$ Radial growth of fungal colony on treatment plate, $r=$ Radial growth of fungal colony on control plate.

Antagonist assay of $B$. subtilis' supernatant on $N$. dimidiatum. The antifungal activity of the supernatant obtained from a B. subtilis ABS-S14 culture on the growth of $N$. dimidiatum was tested. PDA plates were prepared supplemented with $50.0 \%, 25.0 \%, 12.5 \%, 6.2 \%$, and $3.1 \%(\mathrm{v} / \mathrm{v})$ of the sterilized cell-free supernatant. B. subtilis was cultured in $\mathrm{LB}$ medium at $37^{\circ} \mathrm{C}$ with continuous shaking for $72 \mathrm{~h}$ and the vegetative cells and endospores were removed by centrifugation at $8,000 \times g$ for $20 \mathrm{~min}$. The resulting supernatant was sterilized by autoclaving at $121^{\circ} \mathrm{C}$ for 20 $\mathrm{min}$. The sterilized supernatant was diluted with sterile distilled water to various concentrations. The diluted supernatant was mixed well with melted PDA (2-fold concentration) at a ratio of $1: 1$, then poured into a $4.5 \mathrm{~cm}$ diameter plate. An active mycelial plug from a 2-day-old colony of $N$. dimidiatum $(0.1 \mathrm{~cm})$ was placed on the center of each plate and further incubated at $25^{\circ} \mathrm{C}$ for 3 days or until a fungusonly control had grown so that the mycelial edge reached the rim of the PDA medium. The radial growth of the $N$. dimidiatum mycelium was measured and the percentage of mycelial growth inhibition was calculated as shown above (Gamliel et al., 1989). The trial was repeated twice with 4 replications.

Effect of sodium bicarbonate on $N$. dimidiatum. The effect of sodium bicarbonate on the growth of $N$. dimidiatum was tested. PDA plates were prepared supplemented with $2.0 \%, 1.0 \%, 0.5 \%, 0.25 \%$, and $0.125 \%(\mathrm{v} / \mathrm{v})$ of sodium bicarbonate. The PDA powder was dissolved with each sodium bicarbonate concentration then autoclaved at $121^{\circ} \mathrm{C}$ for $20 \mathrm{~min}$ prior to pouring onto the plates $(4.5 \mathrm{~cm}$ diameter). An active mycelial plug from a 2-day-old colony of $N$. dimidiatum $(0.1 \mathrm{~cm})$ was placed on the center of each PDA plate supplemented with sodium bicarbonate and incubated at $25^{\circ} \mathrm{C}$ for 3 days or until a fungus-only control had grown so that the mycelial edge reached the rim of the PDA medium. The radial growth of the $N$. dimidiatum mycelium was measured and the percentage of mycelial growth inhibition was calculated as shown above (Gamliel et al., 1989). The trial was repeated twice with 4 replications. Moreover, the selected concentration (100\% inhibition on $N$. dimidiatum growth) of $B$. subtilis' supernatant and sodium bicarbonate was also mixed for antagonistic assay on the growth of $N$. dimidiatum.

Assay of stem brown spot disease control. The in vivo assay was carried out at infected orchards in Hat Yai district. Thailand. Parts of dragon fruit plants infected by stem brown spot disease were pruned and four preventive treatments each with three replications of 21 poles were applied in a randomized block design. The four treatments applied to the pruned plants were as follows: (1) sterile distilled water (control), (2) $1 \%$ sodium bicarbonate, (3) 50\% supernatant, and (4) a combination of supernatant and sodium bicarbonate, which final concentration were $50 \%$ and $1 \%$, respectively. Each treatment was sprayed onto the pruned plants once a week for 4 months. The incidence of stem brown spot disease was measured based on visible signs of initial disease invasion, in the form of minute chlorotic depressed spots. To confirm the causing agent, the initial disease symptom was also isolated for causing agent as 2.3. In the investigation of curative treatment, the infected dragon fruit plants were pruned except for a single branch which had at least 20 disease spots. These were divided into two curative treatment groups. In the first, the infected branch was sprayed with a combination of supernatant and sodium bicarbonate twice a week while in the second the disease spot was removed with a sterile scalpel prior to the application of the combination of supernatant and sodium bicarbonate. The development of the disease was investigated after treatment for a month. This experiment was repeated in consecutive seasons within the same orchard. 


\section{Induced resistance of coated fruit}

Plant tissue preparation. Dragon fruit plants were grown for 2 months or until the second branch generated was 20 $\mathrm{cm}$ long, under the greenhouse conditions. An artificial wound ( $3 \mathrm{~mm}$ deep) was made on this second branch using a sterile needle. The wounded cladodes were divided into four groups and treated on the artificial wound with $20 \mu 1$ each of four treatments: (1) sterile distilled water (control), (2) $1 \%$ sodium bicarbonate, (3) $50 \%$ supernatant, and (4) a combination of supernatant and sodium bicarbonate, which final concentration were $50 \%$ and $1 \%$, respectively. The green part of the treated cladode in a $0.5 \mathrm{~cm}$ area around each of the wound sites was removed at 12, 24, 48, and 72 $\mathrm{h}$ post treatment and immediately frozen in liquid nitrogen then stored at $-80^{\circ} \mathrm{C}$ until the time of the enzyme activity assay.

Enzyme activity. Tissue samples (200 mg) were ground into a fine powder with a mortar and pestle under liquid nitrogen. Total proteins were extracted with $100 \mathrm{mM}$ phosphate buffer ( $\mathrm{pH}$ 7.0) and precipitated using ammonium sulfate (Wingfield, 2016). The resulting protein was estimated according to Bradford (1976). The activities of $\beta$-1,3-glucanas (GLU), chitinase (CHI), phenylalanine ammonia-lyase (PAL), and peroxidase (POD) were determined from three replicate samples using the colorimetric method and repeated twice.

GLU activity was assayed by the reducing-sugar method according to Abeles and Forrence (1970) using laminarin as a substrate in the reaction. For the enzyme activity assay, $100 \mu \mathrm{l}$ of the extracted protein was thoroughly mixed with $100 \mu 1$ of $2 \%(\mathrm{w} / \mathrm{v})$ laminarin, and the final volume of the reaction was adjusted to be $1 \mathrm{ml}$ with $0.1 \mathrm{M}$ sodium acetate buffer (pH 5.0). The reaction was incubated at $50^{\circ} \mathrm{C}$ for 30 $\min$. At the end of incubation, the reaction was stopped by adding $1 \mathrm{ml}$ of dinitrosalicylic acid solution and placing the mixture in boiling water for $5 \mathrm{~min}$. The enzyme activity was determined by measuring the absorbance against 540 $\mathrm{nm}$. Various concentrations of glucose were used for the standard curve assay and the activity was expressed in $\mu \mathrm{g}$ of glucose per h per mg of total protein ( $\mu \mathrm{g} / \mathrm{h} / \mathrm{mgP})$.

$\mathrm{CHI}$ activity was detected from the reducing-sugar, Nacetyl glucosamine degraded from chitin, following the method of Miller (1959) with minor modification. The enzyme activity was assayed by incubating a reaction mixture consisting of $100 \mu \mathrm{l}$ of the extracted protein, $100 \mu \mathrm{l}$ of $1 \%$ (w/v) colloidal chitin and $800 \mu \mathrm{l}$ of $0.1 \mathrm{M}$ sodium acetate buffer ( $\mathrm{pH}$ 5.0). The reaction was allowed to proceed for $15 \mathrm{~min}$ at $37^{\circ} \mathrm{C}$, then stopped by adding $1 \mathrm{ml}$ of dinitrosalicylic acid solution then placing the mixture in boiling water for $5 \mathrm{~min}$. The enzyme activity was determined by measuring the absorbance against $540 \mathrm{~nm}$. Various concentrations of N-acetyl glucosamine were used for the standard curve assay and the activity was expressed in $\mu \mathrm{g}$ of glucose per $\mathrm{h}$ per mg of total protein $(\mu \mathrm{g} / \mathrm{h} / \mathrm{mgP})$.

PAL activity was determined through the conversation rate of L-phenylalanine to trans-cinnamic acid, according to the method of Waewthongrak et al. (2015) with minor modification. The reaction contained $100 \mu 1$ of the extracted protein, $1,400 \mu 1$ of $100 \mathrm{mM}$ Tri-HCl buffer ( $\mathrm{pH} 8.5$ ), and $500 \mu \mathrm{l}$ of $0.1 \mathrm{M}$ L-phenylalanine. The mixture was incubated for $1 \mathrm{~h}$ at $40^{\circ} \mathrm{C}$. The absorbance of the product, cinnamic acid, was measured at $290 \mathrm{~nm}$. The activity of PAL was expressed in $\mu \mathrm{mol}$ of trans-cinnamic acid per $h$ per mg of total protein $(\mu \mathrm{mol} / \mathrm{h} / \mathrm{mgP})$.

POD activity was assayed according to Waewthongrak et al. (2014) with minor modification. The reaction contained $100 \mu \mathrm{l}$ of the extracted protein, $220 \mu 1$ of $0.3 \%$ (v/v) guaiacol, and $20 \mu \mathrm{l}$ of $\mathrm{H}_{2} \mathrm{O}_{2}$ in a total volume of $1 \mathrm{ml}$, adjusted by $10 \mathrm{mM}$ sodium phosphate buffer ( $\mathrm{pH}$ 6.0), which was then well mixed and the absorbance against $470 \mathrm{~nm}$ immediately recorded every $3 \mathrm{~s}$ for $1.5 \mathrm{~min}$. The reaction without $\mathrm{H}_{2} \mathrm{O}_{2}$ served as a blank. The maximum slope was calculated for the enzyme activity that oxidized $1 \mu$ mole of guaiacol in 1 min (unit) which was expressed in units per $\mathrm{mg}$ of total protein (unit/mgP).

Lignin deposition. The wounded fruit were sectioned in the area of the flavedo tissue at the wounding sites following 7 days of treatment. Lignin was stained with Wiesner reagents according to Vallet et al. (1996), and observed using a compound light microscope.

Statistical analysis. The experimental data were subjected to analysis of variance (ANOVA) and the differences were established using Tukey's range test. Differences at $P \leq 0.05$ were considered to be significant.

\section{Results}

Effect of $B$. subtilis on the growth of pathogenic fungus. The inhibitory effect of $B$. subtilis cell and its supernatant was evaluated on the growth of $N$. dimidiatum. The dualculture test between the cells of $B$. subtilis and the active mycelium of $N$. dimidiatum revealed strong suppression of $99.8 \%$ on the growth of $N$. dimidiatum by as shown in Fig. 1. Interestingly, complete inhibition of $N$. dimidiatum mycelial growth by the 2-fold dilution of cell-free supernatant of $B$. subtilis was observed when the $N$. dimidiatum colony was cultured on the PDA medium supplemented with the 


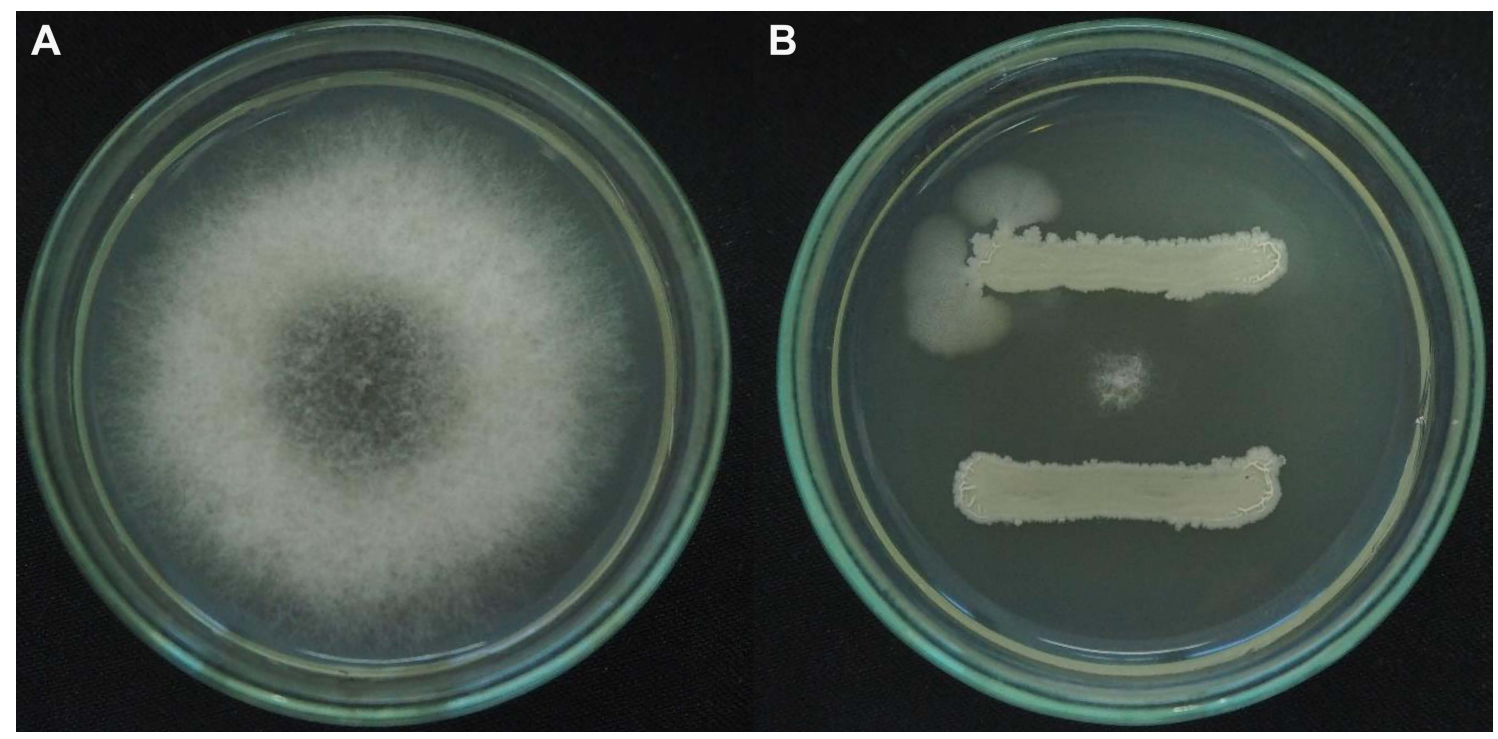

Fig. 1. The effect of Bacillus subtilis on Neoscytalidium dimidiatum growth. N. dimidiatum on potato dextrose agar (PDA) medium alone (control) (A) and N. dimidiatum on PDA medium with B. subtilis (dual-culture test) (B).

supernatant of $B$. subtilis (Table 1). It was noticed that $B$. subtilis was able to produce and secrete the metabolite which acted as an antifungal substance in both solid and liquid media.

Effect of sodium bicarbonate on the growth of pathogenic fungus. The percentage inhibition on the growth of $N$. dimidiatum by sodium bicarbonate was evaluated using PDA medium supplemented with various concentrations of sodium bicarbonate. Complete suppression of the mycelial growth of $N$. dimidiatum was observed when the fungus was grown on the medium supplemented with $2 \%$ and $1 \%$ $(\mathrm{w} / \mathrm{v})$ sodium bicarbonate. And, the combination of sodium bicarbonate $1 \%(\mathrm{w} / \mathrm{v})$ and a 2 -fold dilution of cell-free supernatant of $B$. subtilis also produced complete inhibi-

Table 1. Effect of Bacillus subtilis cell-free supernatant on the fungal agent of stem brown spot disease, Neoscytalidium dimidiatum

\begin{tabular}{cc}
\hline Supernatant concentration (\%) & Mycelial growth inhibition (\%) \\
\hline 100 & $100 \pm 0.00 \mathrm{e}$ \\
50 & $100 \pm 0.00 \mathrm{e}$ \\
25 & $95.66 \pm 2.71 \mathrm{~d}$ \\
12.5 & $79.85 \pm 39.13 \mathrm{c}$ \\
6.25 & $39.96 \pm 21.27 \mathrm{~b}$ \\
0 & $0 \pm 0.00 \mathrm{a}$ \\
\hline
\end{tabular}

Values are presented as mean \pm SE. The variables were analyzed by Tukey's range test to assess mean separation significance. The same letter following disease incident values show no significant difference to each other at $P \leq 0.05$.
Table 2. Effect of sodium bicarbonate solution on the fungal agent of stem brown spot disease, Neoscytalidium dimidiatum

\begin{tabular}{lc}
\hline Sodium bicarbonate (\%) & Mycelial growth inhibition (\%) \\
\hline 2 & $100 \pm 0.00 \mathrm{e}$ \\
1 & $100 \pm 0.00 \mathrm{e}$ \\
0.5 & $79.45 \pm 5.66 \mathrm{~d}$ \\
0.25 & $50.06 \pm 3.23 \mathrm{c}$ \\
0.125 & $33.85 \pm 3.79 \mathrm{~b}$ \\
0 & $0 \pm 0.00 \mathrm{a}$ \\
\hline
\end{tabular}

Values are presented as mean $\pm \mathrm{SE}$. The variables were analyzed by Tukey's range test to assess mean separation significance. The same letter following disease incident values show no significant difference to each other at $P \leq 0.05$.

tion on the mycelial growth of $N$. dimidiatum. However, sodium bicarbonate at concentrations of $0.5 \%, 0.25 \%$, and $0.125 \%(\mathrm{v} / \mathrm{w})$ were only able to retard the colony development by approximately $79 \%, 50 \%$, and $34 \%$, respectively (Table 2).

Effect of $\boldsymbol{B}$. subtilis' supernatant and sodium bicarbonate on stem brown spot disease. In the testing of preventive and curative methods against $N$. dimidiatum infection of dragon fruit plants the preventive treatment comprising a combination between the 2-fold dilution of cell-free supernatant of $B$. subtilis and $1 \%(\mathrm{w} / \mathrm{v})$ sodium bicarbonate was very effective in preventing infection with stem brown spot disease and there was no incidence of disease on the plants thus treated during the entire period of 4 months. However, the treatments of cell-free supernatant of $B$. sub- 
Table 3. Effect of Bacillus subtilis' supernatant and sodium bicarbonate on the development of stem brown spot disease

\begin{tabular}{lc}
\hline \multicolumn{1}{c}{ Treatment } & Disease incidence (\%) \\
\hline Control & $77.8 \pm 11.7 \mathrm{~d}$ \\
$\mathrm{NaHCO}_{3}$ & $11.1 \pm 1.6 \mathrm{c}$ \\
$\mathrm{S}$ & $6.3 \pm 0.8 \mathrm{~b}$ \\
$\mathrm{NaHCO}_{3}+\mathrm{S}$ & $0.0 \pm 0.0 \mathrm{a}$ \\
\hline
\end{tabular}

Values are presented as mean $\pm \mathrm{SE}$; sterile water (control); sodium bicarbonate $\left(\mathrm{NaHCO}_{3}\right)$; B. subtilis cell-free supernatant (S); a combination of $B$. subtilis cell-free supernatant and sodium bicarbonate $\left(\mathrm{NaHCO}_{3}+\mathrm{S}\right)$. The variables were analyzed by Tukey's range test to assess mean separation significance. The same letter following disease incident values show no significant difference to each other at $P$ $\leq 0.05$.

tilis and sodium bicarbonate alone were only able to reduce the incidence of disease development to $93.7 \%$ and $88.9 \%$, respectively. Meanwhile, in the control group the incidence of disease was $77.8 \%$ (Table 3 ).

In the curative investigation, which involved the treatment of 5-20 spots of brown spot disease per branch the treatment using the supernatant of $B$. subtilis and the combination of supernatant with sodium bicarbonate showed the same result both restricted the enlargement of the development of brown spot disease as compared to the treatment with sodium bicarbonate alone and the control group treated with distilled water, in both of which disease development was still observed. However, even though the disease spot was restricted, it was still possible to generate conidia at the spot's center and this was able to be germinated on a PDA plate, indicating that $N$. dimidiatum was able to propagate even though it was exposed to the inhibition treatments. Surprisingly, when the disease spots were removed prior to application of the combination of supernatant and sodium bicarbonate this exhibited a strong curative effective effect which protected the treated cladodes from further invasion, as shown in Fig. 2.

Effect of the supernatant and sodium bicarbonate on defense-related enzymes in dragon fruit plants. The patterns of induction activities of GLU, CHI, PAL, and POD in the cladodes of dragon fruit plants were investigated following treatment for 12, 24, 48, and $72 \mathrm{~h}$ as shown in Fig. 3. There was hardly any effect on any of these defense-related enzyme activities in the cladodes of dragon fruit plants treated with sodium bicarbonate alone when compared to that of the control group. Interestingly, the activities of all the four enzymes were markedly elevated in the dragon fruit plants treated with the supernatant of $B$. subtilis alone, and the combination of supernatant with sodium bicarbonate. The GLU activity reached a maximum level 24 $\mathrm{h}$ post treatment while the $\mathrm{CHI}$ activity was at its highest level $48 \mathrm{~h}$ post treatment with both being reduced $72 \mathrm{~h}$ post treatment. Surprisingly, GLU and CHI activities were
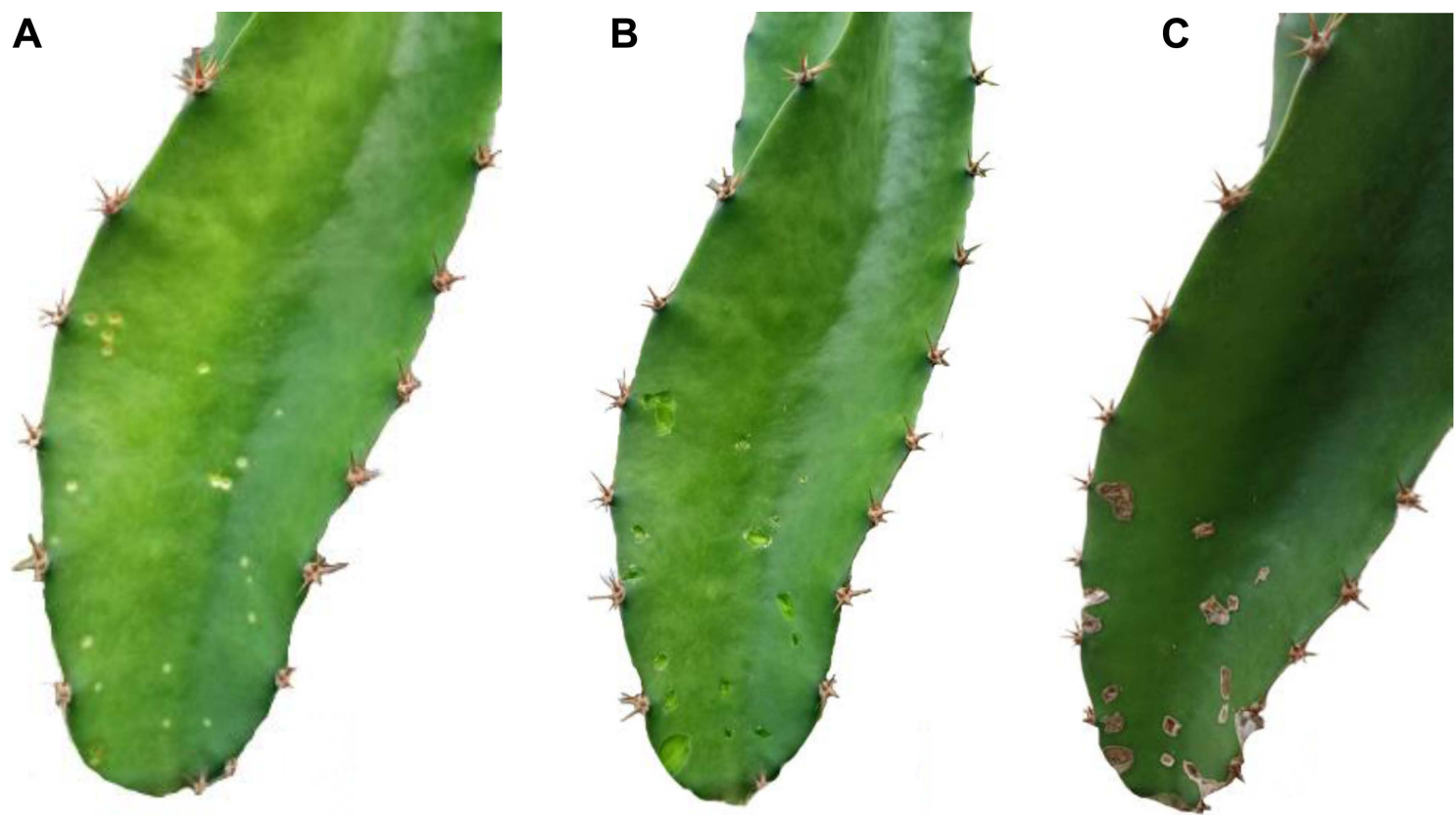

Fig. 2. The curative method using a combination of Bacillus subtilis cell-free supernatant and sodium bicarbonate against stem brown spot disease. The initial symptoms of infected dragon fruit cladode (A), after removing the visible stem brown spot disease (B), and after a month of the treatment with a combination of B. subtilis cell-free supernatant and sodium bicarbonate (C). 

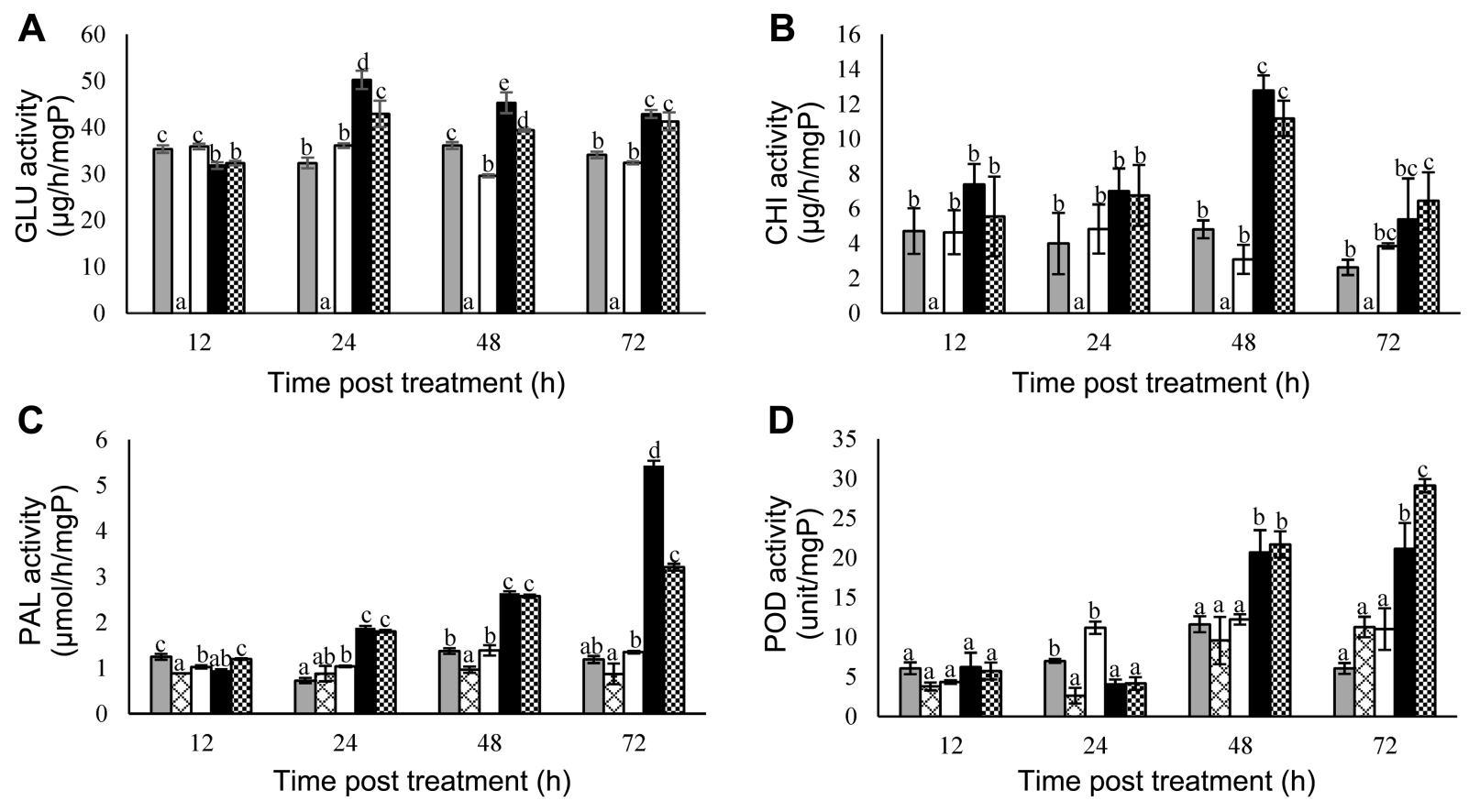

$\square$ Healthy control $\quad \square$ Disease control $\quad \square \mathrm{NaHCO}_{3} \quad \mathbf{S} \quad \mathbf{a} \mathrm{NaHCO}_{3}+\mathrm{S}$

Fig. 3. The activity abundance for defense-related enzymes. $\beta-1,3-G l u c a n a s$ (GLU) (A), chitinase (CHI) (B), phenylalanine ammonialyase (PAL) (C), and peroxidase (POD) (D) in the dragon fruit cladodes after from various treatments; sterile water (healthy control); initial infected cladodes (disease control); sodium bicarbonate $\left(\mathrm{NaHCO}_{3}\right)$; Bacillus subtilis cell-free supernatant (S); a combination of $B$. subtilis cell-free supernatant and sodium bicarbonate $\left(\mathrm{NaHCO}_{3}+\mathrm{S}\right)$. Vertical bars represent standard errors of the mean value of three trials; columns with the same letter above them show no significant difference to each other at $P \leq 0.05$ according to the Tukey's range test.

not detected in the disease control group. Meanwhile, a similar pattern of activity for PAL and POD was observed in which they both gradually increased and reached their highest levels $72 \mathrm{~h}$ post treatment.

Effect of the supernatant and sodium bicarbonate on lignin deposition in dragon fruit cladodes. Lignin depo-

Table 4. lignin deposition in treated cladodes of injured dragon fruit plants

\begin{tabular}{lc}
\hline \multicolumn{1}{c}{ Treatment } & Lignin area $\left(\mu \mathrm{m}^{2}\right)$ \\
\hline Control & $5,400.3 \pm 849.3 \mathrm{a}$ \\
$\mathrm{NaHCO}_{3}$ & $5,748.7 \pm 1,793.7 \mathrm{a}$ \\
$\mathrm{S}$ & $37,044.0 \pm 2,033.1 \mathrm{~b}$ \\
$\mathrm{NaHCO}_{3}+\mathrm{S}$ & $39,800.5 \pm 2,333.9 \mathrm{~b}$ \\
\hline
\end{tabular}

Values are presented as mean $\pm \mathrm{SE}$; sterile water (control); sodium bicarbonate $\left(\mathrm{NaHCO}_{3}\right)$; Bacillus subtilis cell-free supernatant (S); a combination of $B$. subtilis cell-free supernatant and sodium bicarbonate $\left(\mathrm{NaHCO}_{3}+\mathrm{S}\right)$. The variables were analyzed by Tukey's range test to assess mean separation significance. The same letter following lignin area values show no significant difference to each other at $P \leq$ 0.05 . sition in the artificial wounds on dragon fruit cladodes was microscopically detected on day 7 following treatment with the supernatant and sodium bicarbonate and the results are shown in Table 4 and Fig. 4. The dragon fruit cladodes with artificial wounds treated with sodium bicarbonate alone showed a similar result with control group, with were only a slight deposition of lignin represented by red-pink areas around the wounds. Meanwhile, the cladodes treated with the supernatant alone and the combination of supernatant and sodium bicarbonate were able to synthesize substantial amounts of lignin to cure the damaged tissue, with lignin deposition extending approximately $50 \mu \mathrm{m}$ into the cells around the artificial wounds.

\section{Discussion}

There has been some confusion in respect of the agent causing stem brown spot disease in all species of dragon fruit plants. Nigrospora sphaerica was firstly reported to be the causal pathogen of stem brown spot disease (Ellis, 1971) while Valencia-Botín et al. (2003), who named this disease, fish-eye because of the appearance of the chlorotic 


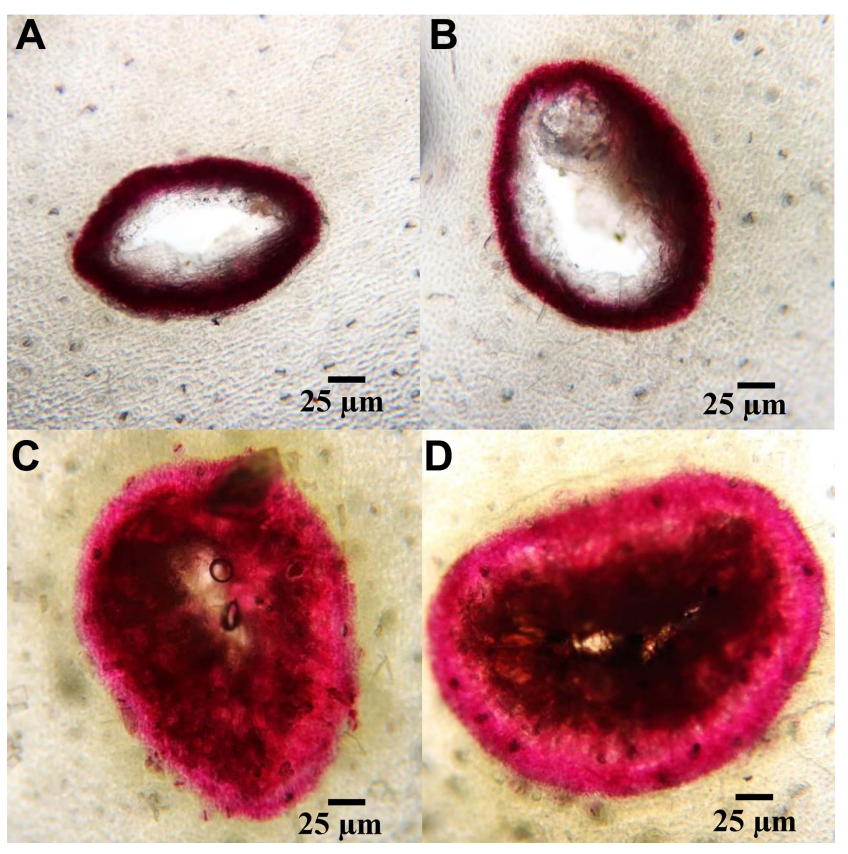

Fig. 4. Lignin deposition in epidermal tissues of dragon fruit cladodes under $40 \times$ magnification using a compound light microscope obtained on day 7 after treatments: sterile water (A); sodium bicarbonate (B); Bacillus subtilis cell-free supernatant (C); and a combination of $B$. subtilis cell-free supernatant and sodium bicarbonate (D). Red-pink areas represent lignin deposition.

points in the cladodes as an early symptom of the disease, reported that it was caused by Botryosphaeria dothidea. However, many recent studies findings have reported that $N$. dimidiatum is a causal agent with some describing the disease as black rot or stem canker (Chuang et al., 2012; Ezra et al., 2013; Lu et al., 2015; Masratul Hawa et al., 2013; Sanahuja et al., 2016; Xu et al., 2018; Yi et al., 2015). The present study also separated and identified the causal agent of stem brown spot disease based on DNA sequencing using the ITS region and confirmed it to be $N$. dimidiatum. This work investigated means of controlling stem brown spot disease in dragon fruit plants using the supernatant from $B$. subtilis in combination with sodium bicarbonate by exploring changes in protein accumulation behavior and lignin deposition in damaged cladodes of dragon fruit plants. Previous studies have revealed that $B$. subtilis has an inhibition effect against taxonomically diverse fungal pathogens including the genera Saccharicola, Cochliobolus, Alternaria, and Fusarium (Hazarika et al., 2019) and This study also demonstrated that B. subtilis was able to strongly inhibit the growth of $N$. dimidiatum by the secretion of antibiotic metabolites into the growing medium, which was a main mode of action of $B$. subtilis against various pathogenic fungi reported by Zhang et al. (2019).
However, previous studies have revealed that the use of an antagonistic microorganism alone might not produce a satisfactory outcome in an in vitro test conducted in the field (Jiwanit et al., 2018). Sodium bicarbonate has been widely reported to be an antimicrobial agent (reviewed in Marín et al., 2017) and this work also found that a solution of $1 \%(\mathrm{w} /$ v) sodium bicarbonate completely suppressed $N$. dimidiatum growth. Moreover, a mixture of the supernatant from B. subtilis and sodium bicarbonate also showed a strong inhibition effect against the growth of $N$. dimidiatum.

The effective antimicrobial agents secreted by $B$. subtilis especially cycliclipopeptide groups including the iturin, surfactin and fengycin (or plipastatin) families (Ullrich et al., 1991), are able to be precipitated in acid conditions at a $\mathrm{pH}$ of around 2. Therefore, the alkali conditions created by sodium bicarbonate allowed the supernatant from $B$. subtilis to remain active. This finding suggests that the supernatant from $B$. subtilis has a high potential for preventing stem brown spot fungal attack in dragon fruit plants when combined with treatment by sodium bicarbonate and the study found that not only did this combination strongly suppress $N$. dimidiatum growth on a PDA plate but was also effective in preventing infection by stem brown spot disease in dragon fruit plants. Moreover, the investigation of curative treatment, the direct application of the combination of supernatant with sodium bicarbonate on infected cladodes of dragon fruit plants restricted stem brown spot enlargement, even though the fungus was still able to develop and generate spores in the center of the spot. However, this means that stem brown spot disease was still able to proliferate and begin a new disease cycle in the orchard despite the curative treatment applied. Nevertheless, if the disease spot was removed prior to the treatment the damaged cladodes were able to repair themselves by cell wall deposition and no further disease infection was observed. This was a surprising result and indicated that the combination of supernatant from $B$. subtilis and sodium bicarbonate might contribute to the repairing of damaged dragon fruit cladodes. This is consistent with many previous reports that $B$. subtilis has the potential to influence the induction of plant defense against certain diseases including pistachio nut (Farzaneh et al., 2016), citrus huanglongbing (Munir et al., 2020), bacterial spot disease (Chandrasekaran et al., 2019), and postharvest fungal disease (Zhang et al., 2019).

In this study, whether defense mechanisms were induced in dragon fruit plants to protect themselves from disease invasion was investigated by determining the accumulation of proteins implicated in induced systemic resistance, including pathogenesis-related proteins and enzymes involved in the phenylpropanoid biosynthetic pathway, 
which have been found to be highly expressed after dragon fruit plants were exposed to elicitors (Ali et al., 2014; Tuan et al., 2019). The pathogenesis-related proteins $\mathrm{CHI}$ and GLU play an important role in fungal cell-wall degradation and consequently act as antifungal agents toward several pathogenic fungi which cause plant diseases (Sandhu et al., 2017). Nevertheless, the CHI and GLU in susceptible plant could be suppressed by certain pathogenic fungi (Fiorin et al., 2018). Meanwhile, PAL and POD participate in the phenylpropanoid biosynthetic pathway and are crucial factors in plant cell-wall reinforcement. The findings I the present study revealed that the supernatant from B. subtilis alone and the combination of supernatant and sodium bicarbonate were able to elicit CHI, GLU, PAL, and POD activities in dragon fruit plants over the period explored. Moreover, the deposition of lignin, a major factor in plant cell-wall reinforcement, was observed in dragon fruit plants after they had been treated with the supernatant from $B$. subtilis alone and the combination of supernatant and sodium bicarbonate. Spadaro and Droby (2016) suggested that plant disease decay could be reduced when the defense response systems of host plants were triggered.

Therefore, the present study produced strong evidence that the mechanism of action of $B$. subtilis used as a biocontrol agent was able to protect dragon fruit plant from invasion by $N$. dimidiatum and thus control stem brown spot disease.

This study combined the supernatant from B. subtilis culture as a biocontrol agent, and sodium bicarbonate, as a potential means of controlling stem brown spot disease in dragon fruit plants and found that this biocontrol agent contributes to the elicitation of the natural plant defense mechanisms. However, plant may respond better to this biocontrol agent through cladode injuries and the supernatant mixed with sodium bicarbonate improves plant absorption., Finally, absorption may rely on very tiny particles acting as the carriers and the use of nanoparticles, or nanoemulsions, to optimize absorption by dragon fruit cladodes may be effective in increasing the action of this biocontrol agent in controlling plant disease.

\section{Conflicts of Interest}

No potential conflict of interest relevant to this article was reported.

\section{Acknowledgments}

This research was partially funded by the National Research Council of Thailand (NRCT) and Prince of Songkla
University (Grant no. SAT6202080S) whose support is gratefully acknowledged. The authors would also like to thank the Publication Clinic, Research and Development Office, Prince of Songkla University, for technical comments and improving the manuscript.

\section{References}

Abeles, F. B. and Forrence, L. E. 1970. Temporal and hormonal control of $\beta$-1,3-glucanase in Phaseolus vulgaris L. Plant Physiol. 45:395-400.

Ali, A., Zahid, N., Manickam, S., Siddiqui, Y., Alderson, P. G. and Maqbool, M. 2014. Induction of lignin and pathogenesis related proteins in dragon fruit plants in response to submicron chitosan dispersions. Crop Prot. 63:83-88.

Bradford, M. M. 1976. A rapid and sensitive method for the quantitation of microgram quantities of protein utilizing the principle of protein-dye binding. Anal. Biochem. 72:248-254.

Chandrasekaran, M., Paramasivan, M. and Chun, S.-C. 2019. Bacillus subtilis CBR05 induces vitamin B6 biosynthesis in tomato through the de novo pathway in contributing disease resistance against Xanthomonas campestris pv. vesicatoria. Sci. Rep. 9:6495.

Chuang, M. F., Ni, H. F., Yang, H. R., Shu, S. L., Lai, S. Y. and Jiang, Y. L. 2012. First report of stem canker disease of Pitaya (Hylocereus undatus and H. polyrhizus) caused by Neoscytalidium dimidiatum in Taiwan. Plant Dis. 96:906.

Ezra, D., Liarzi, O., Gat, T., Hershcovich, M. and Dudai, M. 2013. First report of internal black rot caused by Neoscytalidium dimidiatum on Hylocereus undatus (Pitahaya) fruit in Israel. Plant Dis. 97:1513.

Ellis, M. B. 1971. Dematiaceous Hyphomycetes. Commonwealth Mycological Institute, Kew, UK. 608 pp.

Farzaneh, M., Shi, Z.-Q., Ahmadzadeh, M., Hu, L.-B. and Ghassempour, A. 2016. Inhibition of the Aspergillus flavus growth and aflatoxin B1 contamination on pistachio nut by fengycin and surfactin-producing Bacillus subtilis UTBSP1. Plant Pathol. J. 32:209-215.

Fiorin, G. L., Sanchéz-Vallet, A., de Toledo Thomazella, D. P., do Prado, P. F. V., do Nascimento, L. C., de Oliveira Figueira, A. V., Thomma, B. P. H. J., Pereira, G. A. G. and Teixeira, P. J. P. L. 2018. Suppression of plant immunity by fungal chitinaselike effectors. Curr. Biol. 28:3023-3030.

Gamliel, A., Katan, J. and Cohen, E. 1989. Toxicity of chloronitrobenzenes to Fusarium oxysporum and Rhizoctonia solani as related to their structure. Phytoparasitica 17:101-106.

Hazarika, D. J., Goswami, G., Gautom, T., Parveen, A., Das, P., Barooah, M. and Boro, R. C. 2019. Lipopeptide mediated biocontrol activity of endophytic Bacillus subtilis against fungal phytopathogens. BMC Microbiol. 19:71.

Ippolito, A., Schena, L., Pentimone, I. and Nigro, F. 2005. Control of postharvest rots of sweet cherries by pre- and postharvest applications of Aureobasidium pullulans in combination with calcium chloride or sodium bicarbonate. Postharvest Biol. 
Technol. 36:245-252.

Jiwanit, P., Pitakpornpreecha, T., Pisuchpen, S. and Leelasuphakul, W. 2018. The use of Aloe vera gel coating supplemented with Pichia guilliermondii BCC5389 for enhancement of defenserelated gene expression and secondary metabolism in mandarins to prevent postharvest losses from green mold rot. Biol. Control 117:43-51.

Lu, Z., Lu, X., Qin, B., Cheng, M., Huang, L., Chen, B. and Liao, Y. 2015. Identification of pathogen of pitaya stem canker disease in Fangchenggang city of Guangxi. J. South. Agric. 46:1606-1612.

Luong, H. T., Kieu, B. T. N., Vu, T. N., Ha, T. T., Van Tong, H., Hua, T. S., Nguyen, N. Q. and Nguyen, T. H. N. 2016. Study on the possibility of using microorganisms as biological agents to control fungal pathogens Neoscytalidium dimidiatum causing disease of brown spots on the dragon fruit. $J$. Viet. Environ. 8:41-44.

Marín, A., Atarés, L. and Chiralt, A. 2017. Improving function of biocontrol agents incorporated in antifungal fruit coatings: a review. Biocontrol Sci. Technol. 27:1220-1241.

Masratul Hawa, M., Salleh, B. and Latiffah, Z. 2013. Characterization and pathogenicity of Fusarium proliferatum causing stem rot of Hylocereus polyrhizus in Malaysia. Ann. Appl. Biol. 163:269-280.

Miller, G. L. 1959. Use of dinitrisalicylic acid reagent for determination of reducing sugars. Anal. Chem. 31:426-428.

Munir, S., Li, Y., He, P., He, P., Ahmed, A., Wu, Y. and He, Y. 2020. Unraveling the metabolite signature of citrus showing defense response towards Candidatus Liberibacter asiaticus after application of endophyte Bacillus subtilis L1-21. Microbiol. Res. 234:126425.

Sanahuja, G., Lopez, P. and Palmateer, A. J. 2016. First report of Neoscytalidium dimidiatum causing stem and fruit canker of Hylocereus undatus in Florida. Plant Dis. 100:1499-1499.

Sandhu, J. S., Sidhu, M. K. and Yadav, I. S. 2017. Control of fungal diseases in agricultural crops by chitinase and glucanase transgenes. In: Sustainable agriculture reviews, ed. by E. Lichtfouse, pp. 163-212. Springer, Cham, Switzerland.

Spadaro, D. and Droby, S. 2016. Development of biocontrol products for postharvest diseases of fruit: the importance of elucidating the mechanisms of action of yeast antagonists. Trends Food Sci. Technol. 47:39-49.

Tuan, L. N. A., Du, B. D., Ha, L. D. T., Dzung, L. T. K., Phu, D. V. and Hien, N. Q. 2019. Induction of chitinase and brown spot disease tesistance by oligochitosan and nanosilica-oligochitosan in dragon fruit plants. Agric. Res. 8:184-190.

Ullrich, C., Kluge, B., Palacz, Z. and Vater, J. 1991. Cell-free biosynthesis of surfactin, a cyclic lipopeptide produced by Bacillus subtilis. Biochemistry 30:6503-6508.

Valencia-Botín, A. J., Sandoval-Islas, J. S., Cárdenas-Soriano, E., Michailides, T. J. and Rendón-Sánchez, G. 2003. Botryosphaeria dothidea causing stem spots on Hylocereus undatus in Mexico. Plant Pathol. 52:803.

Vallet, C., Chabbert, B., Czaninski, Y. and Monties, B. 1996. Histochemistry of lignin deposition during sclerenchyma differentiation in alfalfa stems. Ann. Bot. 78:625-632.

Waewthongrak, W., Leelasuphakul, W. and McCollum, G. 2014. Cyclic lipopeptides from Bacillus subtilis ABS-S14 elicit defense-related gene expression in citrus fruit. PLOS ONE 9:e109386.

Waewthongrak, W., Pisuchpen, S. and Leelasuphakul, W. 2015. Effect of Bacillus subtilis and chitosan applications on green mold (Penicilium digitatum Sacc.) decay in citrus fruit. Postharvest Biol. Technol. 99:44-49.

Wingfield, P. T. 2016. Protein precipitation using ammonium sulfate. Curr. Protoc. Protein Sci. 84:A.3F.1-A.3F.9.

Xu, M., Peng, Y., Qi, Z., Yan, Z., Yang, L., He, M.-D., Li, Q.X., Liu, C.-L., Ruan, Y.-Z., Wei, S.-S., Xie, J., Xia, Y.-Q. and Tang, H. 2018. Identification of Neoscytalidium dimidiatum causing canker disease of pitaya in Hainan, China. Australas. Plant Pathol. 47:547-553.

Yi, R. H., Ling Lin, Q., Mo, J. J., Wu, F. F. and Chen, J. 2015. Fruit internal brown rot caused by Neoscytalidium dimidiatum on pitahaya in Guangdong province, China. Australas. Plant Dis. Notes 10:13.

Youssef, K., Sanzani, S. M., Ligorio, A., Ippolito, A. and Terry, L. A. 2014. Sodium carbonate and bicarbonate treatments induce resistance to postharvest green mould on citrus fruit. Postharvest Biol. Technol. 87:61-69.

Zahid, N., Ali, A., Manickam, S., Siddiqui, Y., Alderson, P. G. and Maqbool, M. 2014. Efficacy of curative applications of submicron chitosan dispersions on anthracnose intensity and vegetative growth of dragon fruit plants. Crop Prot. 62:129134.

Zhang, S., Zheng, Q., Xu, B. and Liu, J. 2019. Identification of the fungal pathogens of postharvest disease on peach fruits and the control mechanisms of Bacillus subtilis JK-14. Toxins 11:322. 